\title{
Effects of 1450-ppm Fluoride-containing Toothpastes Associated with Boosters on the Enamel Remineralization and Surface Roughness after Cariogenic Challenge
}

\author{
Pedro Luiz Santos Tomaz ${ }^{1}$ Letícia Almeida de Sousa ${ }^{1}$ Kayanne Freire de Aguiar ${ }^{1}$ \\ Thales de Sá Oliveira ${ }^{1}$ Marcelo Henrick Maia Matochek ${ }^{1}$ Mackeler Ramos Polassi ${ }^{1}$ \\ Paulo Henrique Perlatti D’Alpino ${ }^{1}$
} ${ }^{1}$ Biotechnology and Innovation in Health Program,
Universidade Anhanguera de São Paulo (UNIAN-SP), São Paulo,
São Paulo, Brazil

Eur ] Dent 2020;14:161-170

\begin{abstract}
Address for correspondence Paulo Henrique Perlatti D’Alpino, DDS, MSc, PhD, Programa de Pós-Graduação em Biotecnologia e Inovação em Saúde, Universidade Anhanguera de São Paulo-UNIAN SP, Av. Raimundo Pereira de Magalhães, 3.305, São Paulo-SP, Brazil CEP, 05145-200, (e-mail: paulodalpino@gmail.com).
\end{abstract}

\begin{abstract}
Objectives This in vitro study investigated the remineralization potential of 1450 ppm, fluoride-containing toothpastes containing different active remineralization agents after cariogenic challenge with $\mathrm{pH}$ cycling. The enamel surface roughness after brushing and the chemical and physical characteristics of the toothpastes tested were also analyzed.

Materials and Methods Fifty-six bovine enamel blocks were obtained $(4 \times 4 \times 6 \mathrm{~mm})$ and divided into three thirds: intact (untreated), demineralized (artificial caries lesion), and treated (caries lesion, pH cycling, and brushing with dentifrices). Seven commercially available fluoride toothpastes (1450 ppm F): three with anti-erosion claims (Candida Professional [CPP], Colgate Total 12 Daily Repair [CDR], Regenerate Enamel Science [RES]); three with desensitizing claims (Bianco Pro Clinical [BPP], Elmex Sensitive [ESS], and Regenerador Diário DentalClean [RDC]); and one standard regular-fluoride toothpaste Colgate Total 12 (CTT) were selected. During pH cycling (demineralization $6 \mathrm{~h}$ /remineralization $18 \mathrm{~h}$ ) for 7 days, the treated third was brushed with the different dentifrices for 10 minutes in a brushing machine before immersion in a remineralizing solution. The Knoop hardness ( $25 \mathrm{~g}, 10$ second of the surface, and longitudinal section were then evaluated at eight depths (10 to $330 \mu \mathrm{m})$. Mean and percentage of surface hardness recovery (\% SHR) were calculated. Surface enamel roughness (Ra) was also evaluated. The $\mathrm{pH}$, \%weight of particles, zeta potential, and polydispersity index of toothpaste slurries were also evaluated.

Statistical Analysis Data were statistically analyzed (ANOVA/Tukey, 5\%).

Keywords

- enamel

- hardness

- roughness

- toothpaste

- tooth remineralization enamel subsurface was more effectively remineralized when treated with BPP, ESS, enamel subsurface was more effectively remineralized when treated with BPP, ESS, and RDC. The surface roughness was higher when the demineralized third was treated with CTT, RDC, and RES and after the cariogenic challenge $(p<0.05)$. For some of the products tested, there was no relationship between surface remineralization and subsurface remineralization. Although toothpastes CPP and RDC present the lowest \%SHR
\end{abstract}


means, both products effectively remineralize within the subsurface carious lesion. Regression analysis demonstrated no strong correlations of the enamel surface roughness with the chemical and physical parameters.

Conclusions Most but not all the fluoride toothpastes were able to remineralize the enamel surface. No specific chemical or physical parameter alone correlated with the surface roughness.

\section{Introduction}

Fluoride toothpastes are claimed to prevent tooth decay by reducing the solubility of the enamel and promoting the remineralization of incipient lesions in comparison to nonfluoride toothpaste. ${ }^{1}$ Systematic brushing with a fluoride toothpaste is the main nonprofessional intervention to prevent caries, but the caries-preventive effectiveness varies as a function of different fluoride concentrations in the composition of the products. ${ }^{2}$ Higher fluoride concentrations were found to positively correlate with increased caries control. ${ }^{3}$

The remineralization of caries lesions in enamel is also favored by the availability of calcium and phosphate ions, which are delivered when the fluoride toothpastes stimulate the deposition of ions into the enamel tissue. ${ }^{1}$ Ideally, the remineralization systems should provide calcium, phosphate, and fluoride ions to allow mineral gain at the subsurface instead of a mineral deposition restricted to the enamel surface. ${ }^{1}$ Regardless of the possibility of subsurface mineral gain, the potential of fluoride toothpastes for regenerating the hydroxyapatite within the enamel subsurface was found to be restricted to around $30 \mu \mathrm{m}$ deep into the enamel subsurface. ${ }^{4}$ In addition, the newly formed hydroxyapatite has been found to be structurally lacking and mechanically weaker in comparison to the natural enamel. ${ }^{5}$

Given that most of the standard fluoride toothpastes are considered ineffective for some individuals, ${ }^{6}$ oral care companies have recently launched toothpastes with multiple actions associated with specific clinical indications such as desensitizing and anti-erosive properties. ${ }^{7,8}$ In addition, biomimetic approaches, an alternative mechanism that reproduces the natural process of mineralization, ${ }^{9}$ have been developed to boost enamel remineralization. ${ }^{10}$ These approaches are facilitated by the addition of different boosters or supplements in combination with fluoride application. ${ }^{11,12}$ In this way, several oral care products available at the market contain, besides fluoride, different active ingredients and make claims promising protection for teeth against enamel demineralization. ${ }^{13,14}$ The evolving technology and research on the development of new products aim not only to reduce enamel demineralization but also boost the remineralizing capability of formulations, thus reducing the side effects of conventional fluoride treatments. ${ }^{15}$ Despite these improvements, the action of fluoride in remineralization is still considered the gold standard when compared with other remineralization systems. ${ }^{12,16}$

Changes in toothpaste formulations allowed the addition of a variety of novel active ingredients, which may affect the
$\mathrm{pH}$ and abrasiveness of the toothpaste. The abrasives, which seem to react with the active ingredients, were found to affect the enamel surface, leading to varied enamel surface mineral loss as demonstrated in a previous in vitro study. ${ }^{5}$ The abrasiveness of toothpastes varies with the particle hardness, size, and shape, and with the $\mathrm{pH} .{ }^{17}$ In addition, the mechanical act of brushing, depending on the $\mathrm{pH}$ of a toothpaste, may increase their corrosive effect with consequent enamel wear due to chemical erosion. ${ }^{7}$ The $\mathrm{pH}$ of over-the-counter products varies from acidic to neutral to basic, depending on the additives. Clinically, saliva is a diluting agent, protecting the enamel against dental erosion, by means of salivary flow, pellicle, and buffer capacity, which is stimulated by flavored agents. ${ }^{18}$ These functions minimize the effect of the toothpaste acidity on the tooth tissues. The chemical and physical characteristics of new formulations of toothpastes seem to affect the remineralization effect of fluoride-containing toothpastes in different ways.

This in vitro study aimed at investigating the remineralization potential of commercially available toothpastes that contain different active remineralization components. The present study also evaluated the chemical and physical characteristics of these toothpastes, and the consequences to the enamel surface roughness after brushing associated with the cariogenic challenge of $\mathrm{pH}$ cycling.

\section{Materials and Methods}

\section{Toothpaste Selection}

Toothpastes were selected among commercial products containing 1450 ppm F, as indicated by the manufacturers. The characteristics of the products, as well as their lot numbers and expiration dates, are listed in - Table 1. Colgate Total 12 (CTT) was chosen as the control toothpaste, containing the same fluoride concentration.

\section{Chemical and Physical Analyses of the Toothpaste Slurries}

The $\mathrm{pH}$ in toothpaste slurries (1:3, w/v in distilled water) was determined immediately after preparation in four different samples using a pH electrode (AK95; Akso, São Leopoldo, RS, Brazil), which was calibrated with standards ( $\mathrm{pH} 4.0$ and 7.0). For the analysis of the percent weight of solid particles, $40 \mathrm{~mL}$ of the slurries were weighed and then centrifuged (20 minute, $3000 \mathrm{RFC}, 25^{\circ} \mathrm{C}$ ). ${ }^{5}$ The supernatant was carefully removed, and the residual solids were kept at $40^{\circ} \mathrm{C}$ for 10 days. Then, the dehydrated solid particles were weighed, and the percentage weight of solid particles calculated in 
Table 1 Composition of the toothpastes selected for the study

\begin{tabular}{|c|c|c|c|}
\hline Product & Ingredients & Active Agents & $\begin{array}{l}\text { Lot no. } \\
\text { Exp. Date }\end{array}$ \\
\hline $\begin{array}{l}\text { Bianco ProClinical } \\
\text { (BPC) }\end{array}$ & $\begin{array}{l}\text { Aqua, sorbitol, glycerin, cellulose gum, sodium benzo- } \\
\text { ate, silica, sodium lauryl sulfate, hydroxyapatite, mica, } \\
\text { titanium dioxide, aroma, menthol }\end{array}$ & $\begin{array}{l}1450 \mathrm{ppm}^{-} \text {- (as sodium fluoride) } \\
3 \% \text { Tricalcium phosphate }(\beta-\mathrm{TCP})\end{array}$ & $\begin{array}{l}11549114 \\
11 / 2020\end{array}$ \\
\hline $\begin{array}{l}\text { Candida Protect } \\
\text { Professional } \\
\text { (CPP) }\end{array}$ & $\begin{array}{l}\text { Hydrogenated starch hydrolysate, aqua, hydrate silica, } \\
\text { PEG-8, cocamidopropyl betaine, aroma, cellulose gum, } \\
\text { sodium saccharin, sodium chloride, citric acid, sodium } \\
\text { hydroxide, dicalcium phosphate, glycerin, limonene, } \\
\text { linalool, Cl } 77891\end{array}$ & $\begin{array}{l}1450 \text { ppm F- (as sodium monofluoro- } \\
\text { phosphate) } \\
\text { Oligopeptide-104 (Curolox Technol- } \\
\text { ogy) } \\
\text { Calcium glycerophosphate, }\end{array}$ & $\begin{array}{l}641536 \\
04 / 2020\end{array}$ \\
\hline $\begin{array}{l}\text { Colgate Total } 12^{c} \\
\text { (CTT) }\end{array}$ & $\begin{array}{l}\text { Water, sorbitol, hydrated silica, PVM/MA copolymer, } \\
\text { sodium lauryl sulfate, flavor, carrageenan, sodium } \\
\text { hydroxide, sodium saccharin, Cl } 77891 \text {. }\end{array}$ & $\begin{array}{l}1450 \text { ppm F- (as sodium fluoride) } \\
\text { Triclosan }\end{array}$ & $\begin{array}{l}\text { 7204BR122K } \\
07 / 2020\end{array}$ \\
\hline $\begin{array}{l}\text { Colgate Total Daily } \\
\text { Repair }^{c} \\
\text { (CDR) }\end{array}$ & $\begin{array}{l}\text { Glycerin, aqua, hydrated silica, sodium lauryl sulfate, } \\
\text { aroma, zinc oxide, xanthan gum, poloxamer } 407 \text {, zinc } \\
\text { citrate, cellulose gum, benzyl alcohol, cocamidopropyl } \\
\text { betaine, sodium saccharin, phosphoric acid, mica, sucra- } \\
\text { lose, eugenol, Cl 74260, Cl 77492, Cl } 77891\end{array}$ & $\begin{array}{l}1450 \mathrm{ppm} \mathrm{F}^{-} \text {(as sodium fluoride) } \\
0.30 \% \text { Triclosan } \\
\text { Arginine } \\
\text { Tetrasodium pyrophosphate }\end{array}$ & $\begin{array}{l}\text { 8108BR123D } \\
07 / 2020\end{array}$ \\
\hline $\begin{array}{l}\text { Elmex Sensitive }^{d} \\
\text { (ESS) }\end{array}$ & $\begin{array}{l}\text { Aqua, calcium carbonate, sorbitol, arginine bicarbonate, } \\
\text { hydrated silica, sodium lauryl sulfate, aroma, cellulose } \\
\text { gum, sodium bicarbonate, sodium saccharin, benzyl } \\
\text { alcohol, xanthan gum, Cl 77891, limonene. }\end{array}$ & $\begin{array}{l}1450 \text { ppm F- (as sodium monofluoro- } \\
\text { phosphate) } \\
\text { Pro-Argin and CalSeal technologies } \\
\beta \text {-TCP and Tetrasodium pyrophosphate }\end{array}$ & $\begin{array}{l}\text { 8108PL1124 } \\
03 / 2021\end{array}$ \\
\hline $\begin{array}{l}\text { Regenerador Diário } \\
\text { Dentalclean } \\
\text { (RDC) }\end{array}$ & $\begin{array}{l}\text { Glycerin, silica, sorbitol, sodium lauryl sulfate, aqua, } \\
\text { aroma, PEG-12, cellulose gum, o-phosphoric acid, xyli- } \\
\text { tol, sodium saccharin, triclosan, menthol, mica, sodium } \\
\text { benzoate. }\end{array}$ & $\begin{array}{l}1450 \mathrm{ppm} \mathrm{F}^{-} \text {(as sodium fluoride). } \\
\text { Refix technology } \\
\text { Tetrasodium pyrophosphate }\end{array}$ & $\begin{array}{l}41531 \\
05 / 2021\end{array}$ \\
\hline $\begin{array}{l}\text { Regenerate Enamel } \\
\text { Science }^{f} \\
\text { (RES) }\end{array}$ & $\begin{array}{l}\text { Glycerin, calcium silicate, PEG-8, hydrated silica, trisodi- } \\
\text { um phosphate, sodium phosphate, aqua, PE-60, sodium } \\
\text { lauryl sulfate, aroma, flavor, synthetic fluorphlogopite, } \\
\text { sodium saccharin, polyacrylic acid, tin oxide, limonene, } \\
\text { CI } 77891 \text {. }\end{array}$ & $\begin{array}{l}1450 \mathrm{ppm} \mathrm{F}^{-} \text {(as sodium fluoride and } \\
\text { sodium monofluorophosphate) } \\
\text { NR-5 technology: calcium silicate and } \\
\text { sodium phosphate }\end{array}$ & $\begin{array}{l}181358 C A \\
11 / 2020\end{array}$ \\
\hline
\end{tabular}

Abbreviation: $\beta$-TCP, functionalized $\beta$-tricalcium Phosphate.

aRaymounds Eireli Ind., São Paulo, SP, Brazil.

'Migros, Zurich, Switzerland.

'Colgate-Palmolive Manufacturing, São Bernardo do Campo, SP, Brazil.

${ }^{d}$ Colgate-Palmolive Manufacturing, Swidnica, Poland.

eRabbit Corp, Londrina, PR, Brazil.

fUnilever UK Limited, Leatherhead, Surrey, UK.

relation to the total weight of toothpaste slurry. ${ }^{5}$ The particle size distribution, effective diameter, and polydispersity index were also measured at $22^{\circ} \mathrm{C}$ (Phase Analysis Light ScatteringPALS, 90 Plus, Brookhaven Instruments Corporation, Holtsville, NY, United States) after dilution $(250 \mathrm{mg} / \mathrm{L})$ of slurries in distilled water. ${ }^{19}$ Ten replications for the particle analyses were evaluated $(n=10)$.

\section{Specimen Preparation for the Hardness Analysis}

Fifty-six enamel blocks $(4.0 \times 4.0 \times 6.0 \mathrm{~mm})$ were obtained from bovine incisors using a water-cooled rotating diamond wheel (Isomet, Buehler Ltd., Evanston, IL, United States). Enamel blocks were embedded in epoxy resin (EpoxiCure Epoxy Resin and Hardener, Buehler, Lake Bluff, IL, United States). Surfaces were then wet polished with 600 -grit SiC paper at low-speed and with 1,200-grit SiC paper at highspeed using a polishing machine (Single Grinder Polisher, Buehler, Lake Bluff, IL, United States). The final polishing was performed with 1- $\mu \mathrm{m}$ diamond paste and wet felt wheels (Buehler, Lake Bluff, IL, United States). The baseline surface microhardness $(\mathrm{SH})$ was measured using a microhardness tester (HMV, Microhardness tester, Shimadzu, Kyoto, Japan) with a Knoop indenter, under a static load of $25 \mathrm{~g}$ for $5 \mathrm{sec}-$ ond. This was performed to select enamel blocks with $285 \pm$ 30 Knoop hardness number (KHN).

\section{Caries-Like Lesion Formation}

One-third of the surface of the enamel blocks was covered with two consecutive layers of acid-resistant varnish (quick drying nail polish; Colorama, São Paulo, SP, Brazil), and enamel specimens were subjected to demineralization. The enamel blocks were immersed in $30 \mathrm{~mL}$ of $50 \mathrm{mM}$ acetate buffer solution containing $3 \mathrm{mM} \mathrm{CaCl} \cdot \mathrm{H}_{2} \mathrm{O}, 3 \mathrm{mM} \mathrm{KH}_{2} \mathrm{PO}_{4}$, $50 \mathrm{mM}$ lactic buffer, and $6 \mu \mathrm{M}$ methylhydroxydiphosphate (MHDP), at pH 5.0 for 5 days to demineralize the enamel and produce caries-like lesions..$^{20}$ Then, the enamel blocks were covered again to leave only one-third of their exposed surface and then treated with toothpaste slurries. In this way, the enamel block surfaces were divided into three thirds: (1) intact mineralized third, covered with acid-resistant varnish and not exposed to the demineralization solution or toothpaste treatments; (2) demineralized third-protected 
with an acid-resistant varnish after demineralization, as an impeditive for the contact with the toothpastes; and (3) remineralized third-demineralized and treated with toothpaste slurries.

\section{pH Cycling}

After demineralization and covering two-thirds of the enamel surface with an acid-resistant varnish, specimens were randomly distributed according to the treatment $(n=8)$. All enamel blocks were submitted to $\mathrm{pH}$ cycling by interchanging a demineralization solution $\left(1.5 \mathrm{mM} \mathrm{CaCl}_{2}, 0.9 \mathrm{mM} \mathrm{K \textrm {K } _ { 2 }} \mathrm{PO}_{4}\right.$, $50 \mathrm{mM}$ lactic buffer, pH 5.0, 8 hour) and a remineralization solution ( $5 \mathrm{mM} \mathrm{CaCl}_{2}, 0.9 \mathrm{mM} \mathrm{KH}_{2} \mathrm{PO}_{4}, 130 \mathrm{mM} \mathrm{KCl}, 20 \mathrm{mM}$ HEPES, $5 \mathrm{mM} \mathrm{NaN}_{3}$, pH 7.0, 16 hour) for 7 days. ${ }^{21}$ During the $\mathrm{pH}$ cycling, the enamel surfaces were treated with $30 \mathrm{~mL}$ of the toothpaste slurries in a brushing machine during $\mathrm{pH}$ cycling. Brushing was performed between the incubation with the remineralization and the demineralizing solutions. The enamel blocks were brushed with toothpaste slurries ( $1: 3 \mathrm{w} / \mathrm{w}, 2 \mathrm{~mL} / \mathrm{block})$ in a Brushing Simulator Machine MEV2T (Odeme; Joaçaba, SC, Brazil) at a mean temperature of $37^{\circ} \mathrm{C}$ and 120 cycles per minute. A conventional toothbrush with soft bristles (Colgate Classic-Colgate, São Paulo, SP, Brazil) was adapted to the simulator, which brushed the specimens in linear movements with an axial load of $200 \mathrm{~g}$ for 5 minutes. Between the steps, specimens were water rinsed with deionized water.

\section{Dentin Hardness Analysis}

After $\mathrm{pH}$ cycling, enamel surface hardness $\left(\mathrm{SH}_{2}\right)$ was determined using the same parameters above. For this determination, the acid-resistant nail varnish was removed, and hardness of the three thirds of each specimen was tested, with a distance of $100 \mu \mathrm{m}$ between each indentation performed at the center of the thirds. Ten indentations were performed at each area $(n=10)$. The percentage of surface hardness recovery was then calculated ${ }^{7}$ :

$$
\left.\% \mathrm{SHR}=\left(\left(\mathrm{SH}_{2}-\mathrm{SH}_{1}\right) /\left(\mathrm{SH}-\mathrm{SH}_{1}\right)\right) \times 100\right)
$$

\section{Cross-sectional Hardness}

After SH analysis, the bovine enamel specimens were longitudinally sectioned using a water-cooled, rotating diamond wheel at a low-speed, and both half-blocks were used for $\mathrm{CSH}$ measurements. For that, the enamel halves were embedded in epoxy resin and polished, as previously described. The hardness was evaluated at eight depths from the enamel surface $(10,30,50,70,90,110,220$, and $330 \mu \mathrm{m})$. Three indentations were performed at each third, with a distance of $100 \mu \mathrm{m}$.

\section{Surface Roughness}

The roughness average ( $\mathrm{Ra}$ ) was determined in a surface roughness tester (Surftest 401; Mitutoyo, Kawasaki, Japan). For that, three readings were made in the treated, remineralized thirds of the sample $(n=3)$, and the mean surface roughness ( $\mathrm{Ra}$ ) was determined and the results compared. The roughness analysis was performed with preset parameters of $2.85 \mathrm{~mm}$ for the reading extension and $0.8 \mathrm{~mm}$ cutoff.

\section{Surface Morphology}

Two additional specimens treated with the different toothpaste slurries were prepared for surface morphology analysis. The analysis was performed in a SEM (JSM-5310; JEOL, Tokyo, Japan), operating at $10 \mathrm{kV}$. Specimens were previously sputter-coated with gold in a vacuum evaporator (MED 010; Balzers, Balzer, Liechtenstein), and then microscopically analyzed to obtain photomicrographs of the surface morphology of demineralized and remineralized thirds at 5,000× magnification.

\section{Statistical Analysis}

Means and standard deviations were calculated and statistically analyzed with a statistics software (StatSoft; Tulsa, OK, United States). To evaluate normal distribution of the variables, Kolmogorov-Smirnov and Levene tests were used. As the assumptions of the normal distribution was confirmed, data were subjected to one-way analysis of variance, followed by Tukey posthoc test, at a preset $\alpha$ of 0.05 . Regression analysis was performed on the plot of particle size versus percentage weight of particles found in the toothpastes. In addition, regression analysis was also performed by plotting enamel surface roughness versus particle size, versus percentage weight of particles, and versus $\mathrm{pH}$.

\section{Results}

The results of the chemical and physical properties of the toothpaste slurries are depicted in - Table 2. Most of the toothpastes presented nearly neutral to alkaline $\mathrm{pH}$. Only the toothpaste RDC was acidulated. The lowest percentage weight of particles was observed for ESS (46.1\%) and the highest for BPC (61.7\%). The percentage weight of particles was significantly higher for BPC in comparison with the rest of the toothpastes tested. The particle size varied from $296.7 \mathrm{~nm}$ (CPP) to $572.4 \mathrm{~nm}$ (CTT). The toothpastes BPC and RES presented significantly larger particle size in comparison to other products. A moderate positive correlation was found when particle size and percentage weight of particles found in the dentifrices were plotted $\left(R^{2}=0.44\right)$. The zeta potential varied from - $1.9 \mathrm{mV}$ (ESS) to $0.61 \mathrm{mV}$ (RES). Despite the difference among the potential zeta means, no significance was observed when comparing the means. The polydispersity index varied from 0.08 (ESS) to 0.32 (RDC). The polydispersity indexes observed for BPC, RDC, and RES were significantly higher than that of observed in the other products.

The results of the SH analyses are presented in - Table 3. In the mineralized dentin, the SH means varied from 269.1 (RES) to $297.6 \mathrm{KHN}$ (CPP), without significant differences between the groups $(p>0.05)$. No significance was also found when the $\mathrm{SH}_{1}$ means were compared, varying from 192.4 (CDR) TO 240.3 KHN (ESS). The highest surface hardness after $\mathrm{pH}$ cycling, associated with the toothpastes tested $\left(\mathrm{SH}_{2}\right)$, occurred when treated with CTT (296.2 KHN) and the lowest average when treated with RES (273.1 KHN). CTT also favored the highest \%SHR, with a surface recovery of $142.1 \%$. Conversely, the lowest recovery in surface hardness was observed when treated with CPP toothpaste (82.6\%). The 
Table 2 Results of the chemical and physical analyses of the toothpaste slurries

\begin{tabular}{|l|l|l|l|l|l|}
\hline Product & $\mathrm{pH}^{\mathrm{a}}$ & $\begin{array}{l}\text { \% weight of } \\
\text { particles }\end{array}$ & Particle size (nm) & Zeta (mV) & Polydispersity index \\
\hline BPC & $7.92(0.02)$ & $61.7 \mathrm{~A}(1.0)$ & $522.2 \mathrm{~A}, \mathrm{C}(45.3)$ & $-0.09 \mathrm{~A}(1.73)$ & $0.20 \mathrm{~A}, \mathrm{C}, \mathrm{E}(0.04)$ \\
\hline CPP & $7.21(0.02)$ & $43.3 \mathrm{~B}, \mathrm{D}(1.0)$ & $296.7 \mathrm{~B}, \mathrm{D}, \mathrm{F}(25.3)$ & $0.17 \mathrm{~A}(1.87)$ & $0.16 \mathrm{~B}, \mathrm{C}(0.01)$ \\
\hline CTT & $7.51(0.03)$ & $54.4 \mathrm{~B}, \mathrm{C}(1.0)$ & $393.7 \mathrm{~B}, \mathrm{D}, \mathrm{E}(15.7)$ & $-0.15 \mathrm{~A}(1.07)$ & $0.16 \mathrm{~B}, \mathrm{C}(0.03)$ \\
\hline CDR & $7.30(0.02)$ & $48.5 \mathrm{~B}, \mathrm{D}(0.6)$ & $367.3 \mathrm{~B}, \mathrm{D}, \mathrm{F}(19.9)$ & $0.19 \mathrm{~A}(1.74)$ & $0.18 \mathrm{~B}, \mathrm{C}(0.03)$ \\
\hline ESS & $9.16(0.05)$ & $46.7 \mathrm{~B}, \mathrm{D}(0.6)$ & $440.7 \mathrm{~B}, \mathrm{C}, \mathrm{E}(88.8)$ & $-1.9 \mathrm{~A}(1.52)$ & $0.08 \mathrm{~B}, \mathrm{D}, \mathrm{F}(0.04)$ \\
\hline RDC & $4.73(0.03)$ & $55.7 \mathrm{~B}, \mathrm{C}(1.0)$ & $380.7 \mathrm{~B}, \mathrm{D}, \mathrm{E}(14.1)$ & $-0.62 \mathrm{~A}(1.69)$ & $0.31 \mathrm{~A}(0.01)$ \\
\hline RES & $8.92(0.02)$ & $55.0 \mathrm{~B}, \mathrm{C}(1.0)$ & $572.4 \mathrm{~A}, \mathrm{C}(61.9)$ & $0.61 \mathrm{~A}(1.26)$ & $0.22 \mathrm{~A}, \mathrm{C}(0.05)$ \\
\hline
\end{tabular}

Abbreviations: BPC, Bianco ProClinical; CDR, Colgate Total Daily Repair; CPP, Candida Protect Professional; CTT, Colgate Total 12; ESS, Elmex Sensitive; RDC, Regenerador Diário DentalClean; RES, Regenerate Enamel Science.

Note: Means followed by distinct letters (A and B; C and D; E and F) for columns: significant $(p<0.05)$.

${ }^{a}$ All comparisons between mean values were significant $(p<0.05)$.

Table 3 Mean values (standard deviation) of surface hardness analysis $(n=10)$ according to the different treatments

\begin{tabular}{|c|c|c|c|c|}
\hline Product & $\mathrm{SH}$ & $\mathrm{SH}_{1}$ & $\mathrm{SH}_{2}$ & \%SHR \\
\hline BPC & 289.9a (21.9) & 200.8a (19.5) & 290.3a (19.4) & 104.9A (30.5) \\
\hline CPP & 297.6a (28.3) & $211.3 a(25.0)$ & 282.5a (39.1) & $82.3 B(25.6)$ \\
\hline CTT & 280.1a (30.3) & 234.6a (31.0) & 296.2a (33.0) & $142.1 \mathrm{~A}(21.8)$ \\
\hline CDR & 287.7a (31.5) & 192.4a (20.1) & 290.0a (33.4) & $102.6 \mathrm{~A}(8.1)$ \\
\hline ESS & 287.1a (25.4) & $240.3 a(25.8)$ & 285.1a (15.8) & 114.9A (39.3) \\
\hline RDC & $287.1 \mathrm{a}(22.2)$ & 217.5a (25.4) & 277.5a (21.0) & $94.5 \mathrm{~A}(23.9)$ \\
\hline RES & 269.1a (34.2) & 204.3a (30.3) & 273.1 a (33.4) & $112.6 \mathrm{~A}(42.7)$ \\
\hline
\end{tabular}

Abbreviations: BPC, Bianco ProClinical; CDR, Colgate Total Daily Repair; CPP, Candida Protect Professional; CTT, Colgate Total 12; ESS, Elmex Sensitive; RDC, Regenerador Diário DentalClean; RES, Regenerate Enamel Science.

Note: Means followed by distinct lowercase letters, lower case for $\mathrm{SH}, \mathrm{SH}_{1}$, and $\mathrm{SH}_{2}$, and upper cases (A and $\mathbf{B}$ ) for \% $\mathrm{SH}_{\mathrm{R}}$ : $\left.\mathrm{significant} \mathrm{p}<0.05\right)$. $\mathrm{SH}$ : surface hardness (baseline); $\mathrm{SH}_{1}$ : post-demineralization surface hardness; $\mathrm{SH}_{2}$ : surface hardness after $\mathrm{pH}$ cycling.

statistical analysis of the results showed that the means of \%SHR were significantly lower when the treatment was performed with CPP toothpaste compared with the treatment with the CTT control group $(p<0.05)$. Most of the toothpastes tested remineralized the demineralized third close to or more than $100 \%$, according to the calculations of the surface hardness recovery ( - Table 3 ).

- Fig. 1 displays the variations in the longitudinal hardness as a function of depth and the evaluated enamel areas (intact, demineralized, and remineralized thirds). The decrease in the hardness of the demineralized thirds was clearly observed in all the experimental groups in comparison to that of the intact, untreated third, exhibiting a more extensive drop in the shallower subsurface lesion depths. Most results clearly demonstrated overlapping when comparing the longitudinal hardness of the intact with treated conditions ( - Fig. 1). Conversely, the higher superficial hardness recovery of more than $100 \%$ found for BPC and RES had no impact on the longitudinal hardness, demonstrating that the potential of these toothpastes to boost the remineralization of the lesion in comparison with the demineralized condition was less effective. The opposite occurred for CPP and RDC, which were able to significantly reverse the lesion formed to a depth of $110 \mu \mathrm{m}$ for CPP and around $60 \mu \mathrm{m}$ for RDC. This result can be observed in - Fig. 1. The toothpaste
ESS was the exception, exhibiting more than $100 \%$ of surface hardness recovery, effective remineralizing effect to a depth of around $40 \mu \mathrm{m}$, and overlapping means in the deeper areas similar to that observed for the intact, untreated third.

The results of enamel surface roughness after brushing associated with the toothpastes are displayed in - Table 4 . The lowest enamel surface roughness was observed after brushing with BPC (0.193), and the highest with RDC (0.336). Brushing with the toothpaste during the $\mathrm{pH}$ cycling significantly affected the enamel roughness when treated with CTT, RDC, and RES, which exhibited the highest Ra means $(p<0.05)$. Regression analysis demonstrated a weak positive linear correlation when surface roughness was plotted versus particle size $\left(R^{2}=0.0004\right)$ and versus percentage weight of particles $\left(R^{2}=0.047\right)$. Conversely, a weak negative linear correlation was observed when plotting surface roughness with the mean $\mathrm{pH}$ of the toothpastes $\left(R^{2}=0.2244\right)$.

-Fig. 2 displays the surface morphology of the treated, remineralized thirds as a function of the toothpaste used. It was clearly demonstrated that there was a change in the surface morphology after brushing. Despite the differences in the initial morphology among the experimental groups, most of the remineralized areas exhibited smother surface than the demineralized third. 

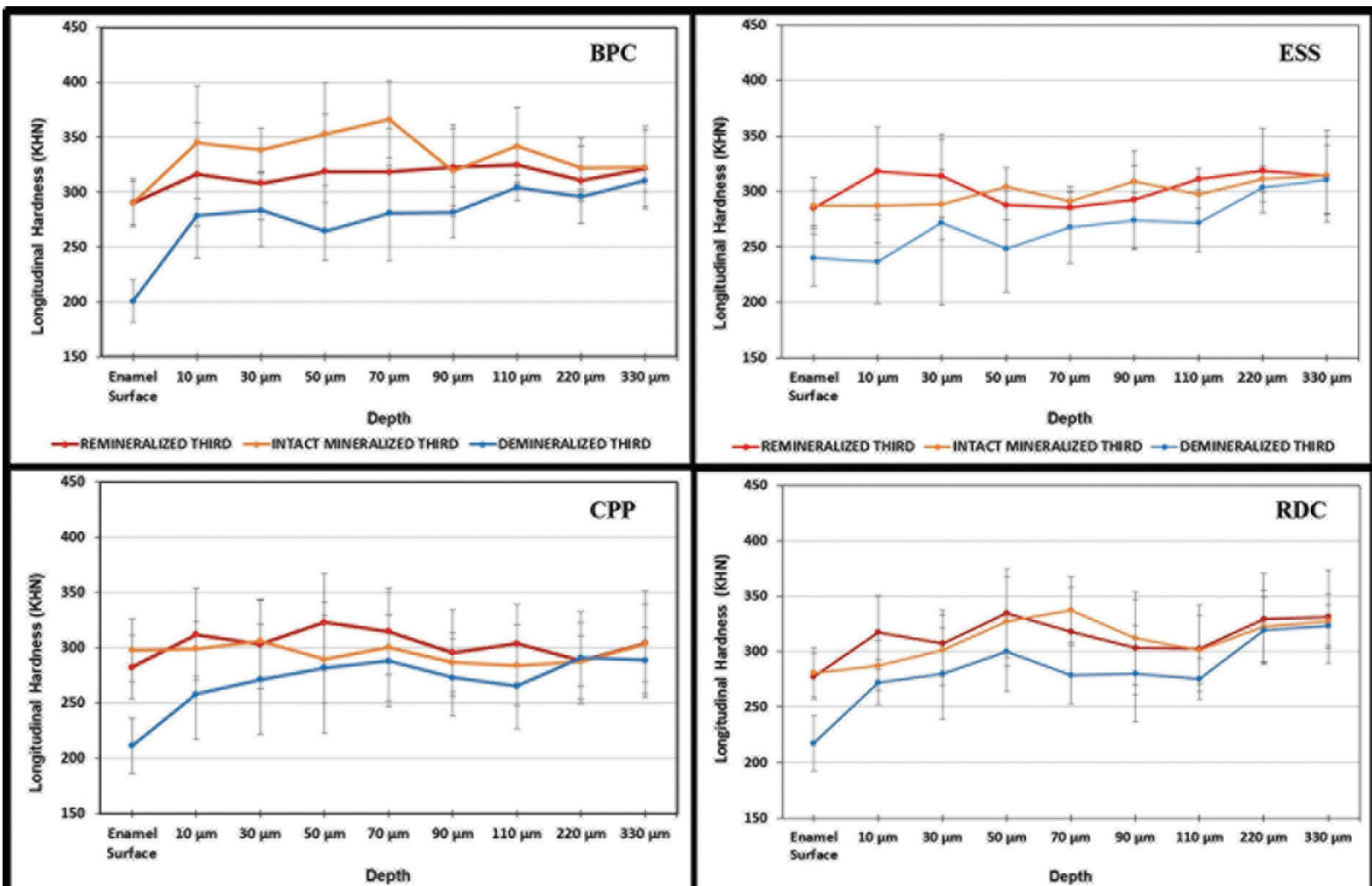

$\rightarrow$ REMINERALIZED THIRD $\rightarrow$ - INTACT MINERAUZED THRD $\rightarrow$ - DEMINERALIZED THIRD

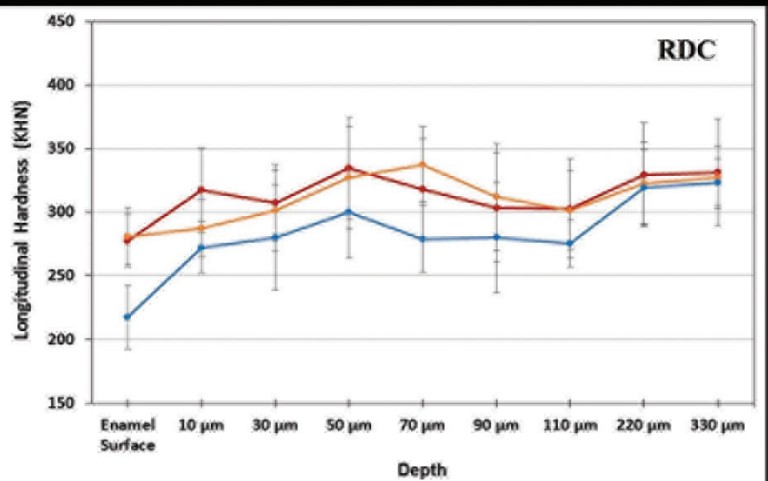

-REMINERAIIZED THIRD - -INTACT MINERAIZZD THIRD —-DEMINERAIIZED THIRD

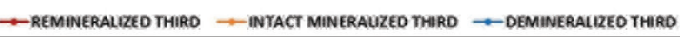

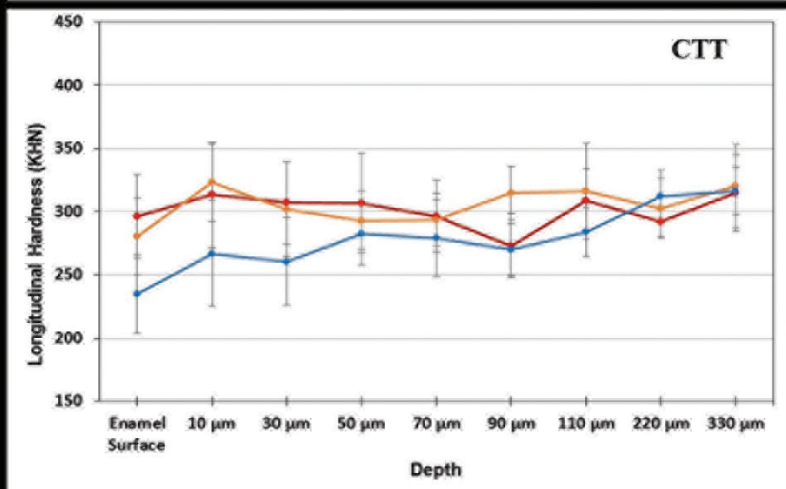

$\rightarrow$ REMINERALZZE THIRD - INTACT MINERALIZED THIRO - DEMINERALIZEO THIRD
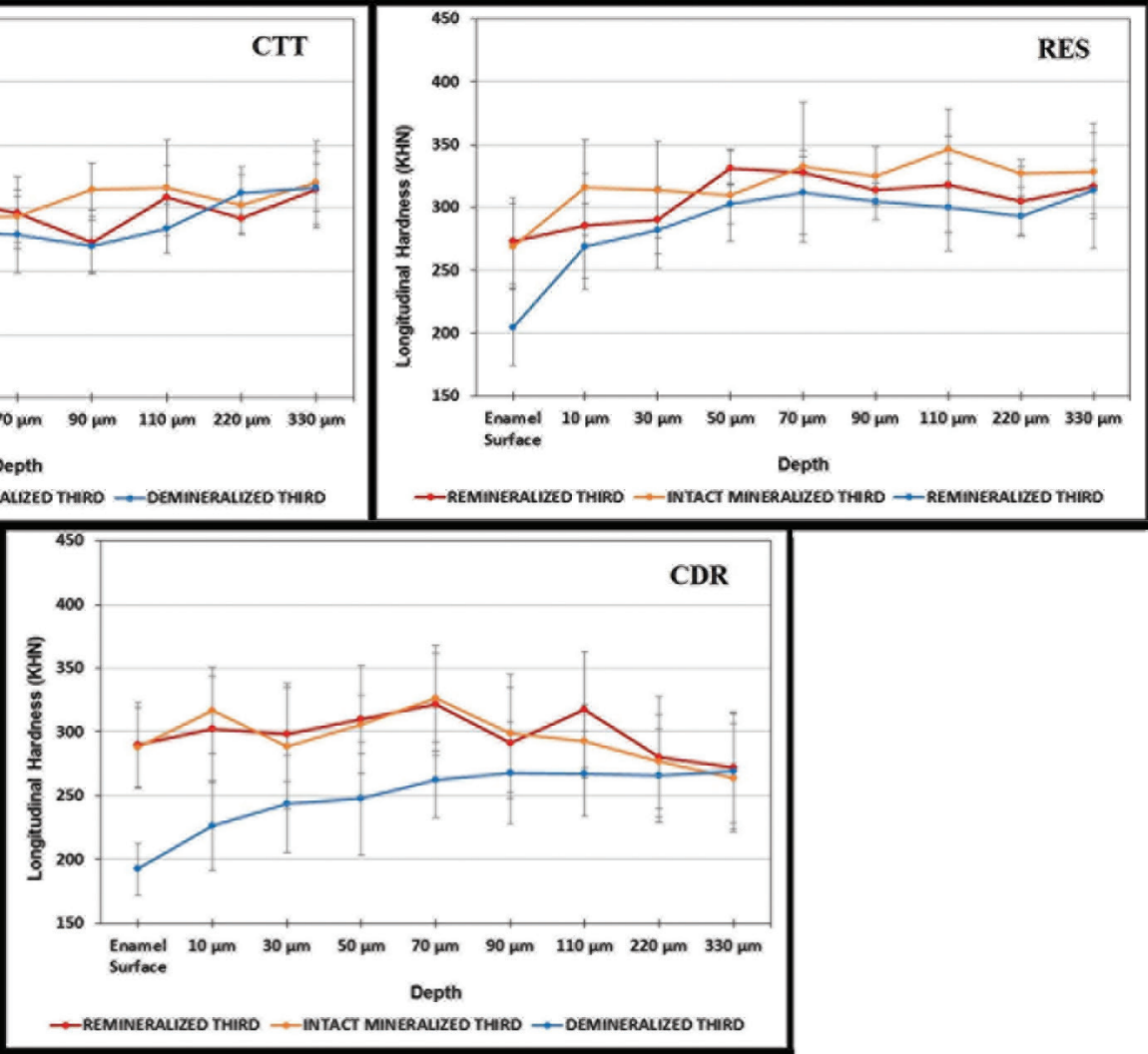

Fig. 1 Cross-sectional hardness (means) at different depths in enamel blocks as a function of the enamel third (intact, demineralized, and remineralized). The bars denote standard deviations. BPC: Bianco ProClinical; CPP: Candida Protect Professional; CTT: Colgate Total 12; CDR: Colgate Total Daily Repair; ESS: Elmex Sensitive; RDC: Regenerador Diário DentalClean; RES: Regenerate Enamel Science. 
Table 4 Mean values (standard deviation) of surface roughness $(\mathrm{Ra})$ of the remineralized third, according to the treatments $(n=3)$

\begin{tabular}{|l|l|}
\hline Treatment & Ra \\
\hline BPC & $0.193(0.005) B, D$ \\
\hline CPP & $0.210(0.010) B$ \\
\hline CTT & $0.303(0.006) A, C$ \\
\hline CDR & $0.266(0.011) B, C$ \\
\hline ESS & $0.223(0.005) B$ \\
\hline RDC & $0.336(0.037) A$ \\
\hline RES & $0.303(0.005) A, C$ \\
\hline
\end{tabular}

Abbreviations: BPC, Bianco ProClinical; CDR, Colgate Total Daily Repair; CPP, Candida Protect Professional; CTT, Colgate Total 12; ESS, Elmex Sensitive; RDC, Regenerador Diário DentalClean; Ra: surface roughness after $\mathrm{pH}$ cycling with the toothpaste slurries (remineralized third); RES, Regenerate Enamel Science.

Note: Means followed by distinct letters (A and B; $\mathbf{C}$ and $\mathbf{D}$ ) for columns: significant $(p<0.05)$.

\section{Discussion}

The results of the present study demonstrated that, by treating the demineralized enamel surface, the toothpastes provided ions that favored the subsurface mineral gain in different ways. Although BPP and RES favored a recovery of enamel surface hardness above $100 \%$, both toothpastes were not as effective in remineralizing the enamel subsurface. For the toothpaste BPP, the means of the cross-sectional hardness of the intact and remineralized thirds only overlapped at a depth of $90 \mu \mathrm{m}$ ( - Fig. 1). For the toothpaste RES, the overlapping between the cross-sectional hardness of the intact and remineralized thirds occurred at a depth of $40 \mu \mathrm{m}$. For the toothpaste CPP, which was the least effective in remineralizing the enamel surface when compared with other products, the opposite was observed. Despite a \%SHR that was significantly lower than that of CTT, CPP was quite effective in remineralizing the enamel in the subsurface. The means of the cross-sectional hardness were equal (at $30 \mu \mathrm{m}$ ) or higher than the means of the intact third up to $220 \mu \mathrm{m}$ ( $\boldsymbol{- F i g}$. 1). Similar results were observed for RDC that was the product which was able to promote the deepest subsurface remineralization effect (to a depth of $60 \mu \mathrm{m}$ ), in comparison to the intact third. The \%SHR was 94\% for RDC. When toothpaste ESS was used, the mean \%SHR was higher than $100 \%$ and the cross-sectional hardness means of the remineralized third were higher than that of the intact third up to approximately $40 \mu \mathrm{m}$ deep. This also proved that ESS was also an effective product for remineralizing both the superficial and the subsurface enamel. The toothpastes CTT and CDR favored the recovery of enamel hardness in relation to the hardness means of the intact third, with overlapping results throughout the comparative depths (-Fig. 1). This indicates that the toothpastes CTT and CDR had a significant effect on reversing the caries-like lesion. Despite these differences, the cross-sectional hardness of the remineralized third treated with all the toothpastes tested was higher than that observed in the demineralized third throughout the analyzed depths.

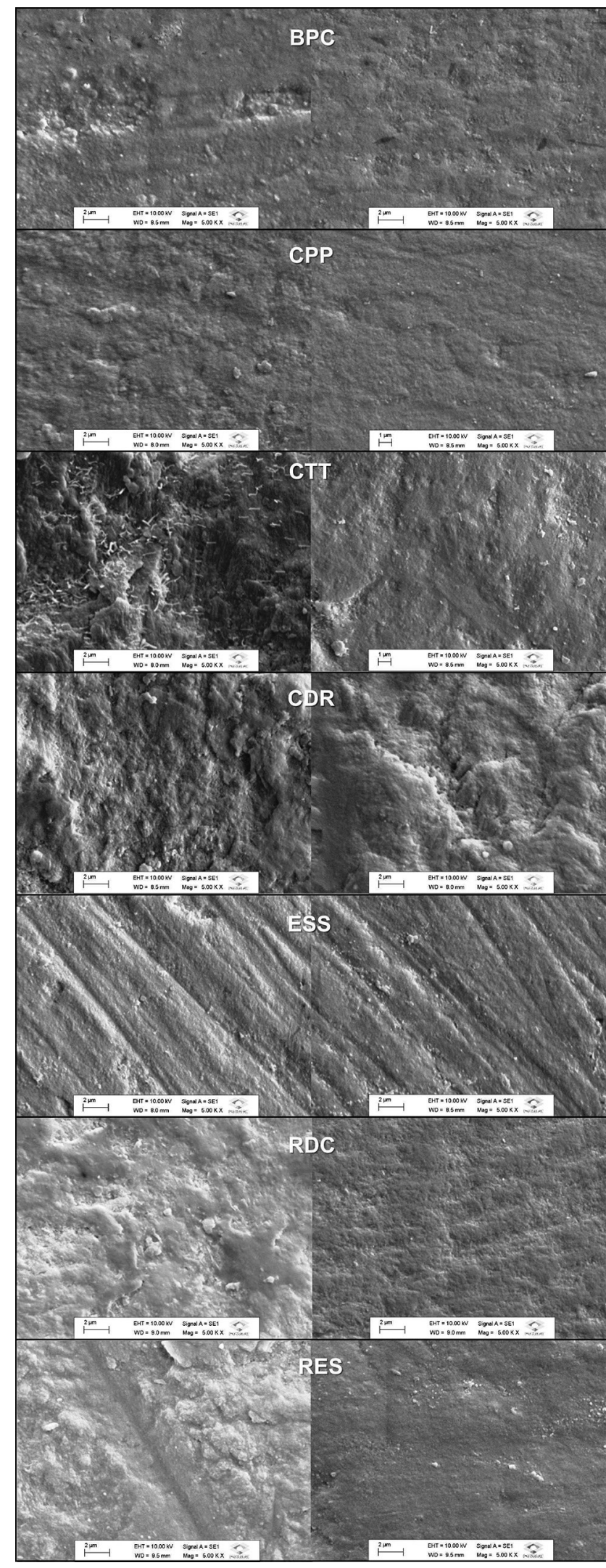

Fig. 2 Representative photomicrographs of the SEM analysis of the demineralized (left) and remineralized, treated thirds (right). BPC: Bianco ProClinical; CPP: Candida Protect Professional; CTT: Colgate Total 12; CDR: Colgate Total Daily Repair; ESS: Elmex Sensitive; RDC: Regenerador Diário DentalClean; RES: Regenerate Enamel Science; SEM, scanning electron microscopy. 
It is important to highlight that manufacturers claim that all toothpastes tested in the present study contain fluoride concentration of $1450 \mathrm{ppm}$ (sodium fluoride and/or monofluorophosphate), with differences in the active ingredients. The mode of action of fluoride against erosion seems to be related to the formation of a calcium fluoride-like ( $\mathrm{CaF}_{2}$-like) layer on the enamel surface, protecting the enamel against erosive substances. ${ }^{7}$ In the advent of an acidic challenge, there is a dissolution that leads to the releasing of ionic fluoride, which can be adsorbed by the enamel crystal avoiding the demineralization process. ${ }^{22}$ Concerns have been expressed over the formation of calcium-phosphate complexes, or the formation of $\mathrm{CaF}_{2}$ when the active ingredient (functionalized $\beta$-tricalcium phosphate- $\beta$-TCP), found in the antierosive toothpaste $\mathrm{BPC}$ is associated with fluoride. The remineralization process is affected by the decrease of the availability of calcium and fluoride ions due to the instability of $\beta$-TCP in water-based preparations. ${ }^{15}$ Despite its ability to recover the enamel surface hardness, this explains the inferior results of BPC to remineralize the subsurface carious lesion. Conversely, the desensitizing toothpaste ESS also contains a declared content of $\beta$-TCP but in association with tetrasodium pyrophosphate and Pro-Argin/CalSeal technologies. This association possibly allowed adequate levels of calcium and phosphate ions in association with the fluoride ions, which positively affected the remineralization of hydroxyapatite crystals of the enamel surface and within the subsurface carious lesion.

Two other toothpastes tested, which were as effective to remineralizing the enamel surface and subsurface, also contain tetrasodium pyrophosphate in association with sodium fluoride (toothpastes anti-erosive CDR and desensitizing $\mathrm{RDC})$. The rationale behind the presence of phosphate in the composition of toothpastes is to oversaturate the tooth tissues with calcium and phosphate, contributing to the decrease of ions on the previously demineralized enamel surface, consequently increasing the resistance to the cariogenic process in the presence of fluoride ions. ${ }^{23}$ RDC also contains proprietary Refix technology, which according to the manufacturer, represents a novel multifunctional phosphate-based dental gel technology in an acidified stabilized phosphates/fluoride complex, which is established especially in saliva. This combination with saliva and dental tooth structures favors the generation of new minerals containing calcium/phosphate/ fluorine, promoting the enamel surface and remineralizing within the subsurface carious lesion.

Conversely, the toothpaste RES contains a declared content of sodium phosphate associated with calcium silicate, using proprietary NR-5 technology. Based on the manufacturer's information, this technology was developed based on the combination of calcium silicate, sodium phosphate salts, and fluoride. The technology is proposed to augment the natural mineralization processes of saliva by nucleation of hydroxyapatite and the formation of tooth enamel minerals. Fluoride-containing toothpastes have been developed with the addition of calcium-containing minerals to boost the remineralization, protecting and repairing the enamel. A previous in vitro study ${ }^{24}$ investigated the reparative and protective after deposition of calcium silicate in acid-eroded enamel surfaces properties; as a consequence, hydroxyapatite (HAP). In this way, calcium silicate was proven to transform into HAP, being deposited on acid-eroded surfaces, providing a protective effect in sound enamel in acidic oral environment. Similar results were observed in another study. ${ }^{17}$ Results of the present study only corroborated the effectiveness of the toothpaste RES in recovering the enamel surface hardness.

The toothpaste CPP, with a claim of antierosive effect, presents a completely different composition that includes a self-assembling peptide, said to induce hydroxyapatite growth, with a protective effect against enamel erosion. ${ }^{25,26}$ CPP also contains calcium glycerophosphate, which is an organic phosphate with affinity for hydroxyapatite, with a proven anticaries effect; it also decreases the enamel demineralization. ${ }^{23,27}$ As previously described, despite the significantly lower \%SHR, this product was quite effective as a remineralizing agent to recover the cross-sectional hardness by up to $220 \mu \mathrm{m}$.

The present in vitro study demonstrated that the combination triclosan/sodium fluoride found in the product CTT was able to remineralize the surface and subsurface enamel lesions in the pH-cycling model of the present study. In a previous in situ enamel remineralization study, ${ }^{28}$ the ability of the combination triclosan/sodium fluoride to enhance remineralization of tooth enamel was evaluated. It was found that the combination triclosan/sodium fluoride presented significantly higher hardness means in comparison to the control groups (sodium fluoride alone and a non-fluoride product), demonstrating an improved mineral recovery.

The differences in chemical composition and physical properties of enamel can also be found in different enamel depths, which will affect the solubility of the tissue. ${ }^{26}$ However, a divergence in the $\mathrm{pH}$ of the products was found. The toothpastes ESS and RES presented the most alkaline $\mathrm{pH}$. The RDC product presented an acid $\mathrm{pH}$ as a function of the proposed technology (Refix technology), whose action is possibly more effective due to the formation of calcium phosphate crystals in an acidic environment, which seems to be the main reason for its effectiveness. The toothpaste slurries were prepared with distilled water, which seems to maintain its low $\mathrm{pH}$, with a high reactivity with enamel structure. ${ }^{7}$ It could be argued that an acidic toothpaste would negatively affect the remineralization process in a previous demineralized enamel tissue. Conversely, it has been previously found that dental hygiene products containing fluoride, which are slightly acidic, were proven to have no erosive potential. ${ }^{27}$ In addition, previous studies demonstrated that acidic formulations had similar anticaries effect in comparison to neutral formulations. ${ }^{28,29}$ In another in vitro study, ${ }^{30}$ the surface texture was evaluated after brushing associated with slurries of different pHs. In that study, it was found that brushing associated with basic toothpaste slurries led to a rougher enamel surface, whereas the acidic slurries formed a relatively smoother texture. It was also pointed out that the acidic smooth promoted a chemically clean surface, possibly minimizing biofilm formation. ${ }^{30}$

The surface roughness of the remineralized third varied as a function of the treatment with the chemical and physical 
characteristics of the toothpastes tested. It could be argued that the extreme $\mathrm{pH}$, either acidic (RDC) or basic (ESS and RES) or even the homogeneity of the particle diffusion in terms of distribution and stability, affect surface roughness. Zeta potential and polydispersity index are two important parameters that demonstrated the possibility of particle aggregation, leading to a consequently increased enamel roughness. In extreme negative and positive zeta potential, the particles are repelling each other, with a lower propensity of particle aggregation. In the advent of particle aggregation, this would lead to the formation of larger-sized particles, with consequent tendency for particle sedimentation. ${ }^{31}$ Low or electrically neutral zeta potential, there may be no forces to prevent the particles from coming together and aggregating. ${ }^{32}$ This would lead to the increase of the enamel roughness. Based on these results, it can be inferred that, except for RDC, most of the toothpastes present relative stability, because an ideal polydispersity index would be lower than $0.20 .^{33}$ The zeta potential varied as a function of the toothpastes, with none of them displaying a tendency to aggregation. The particle size and the percentage weight of particles are also important parameters to analyze. BPC presented the highest percentage weight of particles and the second biggest particle size, but significantly lower Ra means (-Table 4 ). In fact, the synergism among these parameters seems to affect the treated enamel surfaces directly.

In a previous study, the enamel mineral content was found to correlate with the hardness of the enamel. ${ }^{34}$ In this way, the lower the hardness values for the enamel, the lower the mineral content. ${ }^{34}$ This in vitro study demonstrated that the commercial toothpastes used to enhance the remineralization potential varied as a function of different active ingredients in the formulation. From the general analysis of the results, it was observed that all the toothpastes tested favored the recovery of the surface enamel hardness around or higher than $100 \%$. The cross-sectional hardness recovery varied among the different treatments. Another important finding was that the surface hardness recovery does not necessarily reflect the ability of the fluoride toothpaste to remineralize the enamel subsurface completely.

The present study also evaluated the chemical and physical characteristics of these toothpastes and their influence on the enamel surface roughness. In general, it was found that the chemical and physical parameters had no strong correlations with the enamel roughness when the parameters were compared separately. The synergism among these characteristics seems to affect the enamel surface roughness after brushing, following a cariogenic challenge with $\mathrm{pH}$ cycling. This was corroborated by the SEM analysis, which demonstrated a varied surface morphology change after brushing as a function of the toothpastes tested ( - Fig. 2 ).

\section{Conclusions}

From the analysis of the results of the present study, it can be concluded that, except for toothpaste CPP, all the 1450 ppm fluoride-containing toothpastes were able to recover the enamel surface hardness. The cross-sectional hardness varied depending on the toothpaste used to treat the remineralized third. For some of the products tested, there was no relationship between surface remineralization and subsurface remineralization. BPC and RES had no impact on the longitudinal hardness, as observed at the enamel surface, demonstrating that these toothpastes were less effective to boost the remineralization of the lesion in comparison with the demineralized condition. Although toothpastes CPP and RDC present the lowest \%SHR means, both products effectively remineralize within the subsurface carious lesion. All chemical and physical parameters associated seem to interfere with the enamel surface roughness, as no correlations were found when these parameters were analyzed separately versus the enamel roughness.

\section{Funding}

The authors are grateful to Universidade Anhanguera de São Paulo for partially supporting this study. This investigation was also supported by FUNADESP no. 2018-0145.

\section{Conflict of Interest}

None declared.

\section{References}

1 Cochrane NJ, Cai F, Huq NL, Burrow MF, Reynolds EC. New approaches to enhanced remineralization of tooth enamel. J Dent Res 2010;89(11):1187-1197

2 Ganavadiya R, Shekar BRC, Goel P, Hongal SG, Jain M, Gupta R. Comparison of anti-plaque efficacy between a low and high cost dentifrice: a short term randomized double-blind trial. Eur J Dent 2014;8(3):381-388

3 Walsh T, Worthington HV, Glenny AM, Marinho VC, Jeroncic A. Fluoride toothpastes of different concentrations for preventing dental caries. Cochrane Database Syst Rev 2019;3:CD007868

4 Schmidlin P, Zobrist K, Attin T, Wegehaupt F. In vitro re-hardening of artificial enamel caries lesions using enamel matrix proteins or self-assembling peptides. J Appl Oral Sci 2016;24(1):31-36

5 Iijima M, Moradian-Oldak J. Control of apatite crystal growth in a fluoride containing amelogenin-rich matrix. Biomaterials 2005;26(13):1595-1603

6 Nordström A, Birkhed D. Effect of a third application of toothpastes (1450 and $5000 \mathrm{ppm} \mathrm{F}$ ), including a 'massage' method on fluoride retention and $\mathrm{pH}$ drop in plaque. Acta Odontol Scand 2013;71(1):50-56

7 João-Souza SH, Lussi A, Baumann T, Scaramucci T, Aranha ACC, Carvalho TS. Chemical and physical factors of desensitizing and/or anti-erosive toothpastes associated with lower erosive tooth wear. Sci Rep 2017;7(1):17909

8 Izhar F, Nazir MA, Majeed A, Almas K. A study of dentists about their knowledge and practice of dentine hypersensitivity. Eur J Dent 2019;13(4):540-546

9 Cao CY, Mei ML, Li QL, Lo EC, Chu CH. Methods for biomimetic remineralization of human dentine: a systematic review. Int J Mol Sci 2015;16(3):4615-4627

10 Angelova Volponi A, Zaugg LK, Neves V, Liu Y, Sharpe PT. Tooth repair and regeneration. Curr Oral Health Rep 2018;5(4):295-303

11 Xiao Z, Que K, Wang H, et al. Rapid biomimetic remineralization of the demineralized enamel surface using nano-particles of amorphous calcium phosphate guided by chimaeric peptides. Dent Mater 2017;33(11):1217-1228 
12 Elgamily H, Safwat E, Soliman Z, Salama H, El-Sayed H, Anwar M. Antibacterial and remineralization efficacy of casein phosphopeptide, glycomacropeptide nanocomplex, and probiotics in experimental toothpastes: an in vitro comparative study. Eur J Dent 2019;13(3):391-398

13 Smolarek PC, Esmerino LA, Chibinski AC. Bortoluzzi MC, Dos Santos EB, Junior VAK. In vitro antimicrobial evaluation of toothpastes with natural compounds. Eur J Dent 2015;9(4):580-586

14 Farooq I, Ali S, Siddiqui IA, Al-Khalifa KS, Al-Hariri M. Influence of thymoquinone exposure on the micro-hardness of dental enamel: an in vitro study. Eur J Dent 2019;13(3):318-322

15 Delbem ACB, Pessan JP, Alternatives to enhance the anticaries effects of fluoride. In: Coelho Leal S, Takeshita EM, eds. Pediatric Restorative Dentistry. Cham: Springer International Publishing; 2019 75-92

16 Amaechi BT, van Loveren C. Fluorides and non-fluoride remineralization systems. Monogr Oral Sci 2013;23:15-26

17 Hornby K, Ricketts SR, Philpotts CJ, Joiner A, Schemehorn B, Willson R. Enhanced enamel benefits from a novel toothpaste and dual phase gel containing calcium silicate and sodium phosphate salts. J Dent 2014;42(Suppl 1) :S39-S45

18 Lussi A. Erosive tooth wear - a multifactorial condition of growing concern and increasing knowledge. Monogr Oral Sci 2006;20:1-8

19 Mockdeci H, Polonini H, Martins I, Granato AP, Raposo N, Chaves MG. Evaluation of ex vivo effectiveness of commercial desensitizing dentifrices. J Clin Exp Dent 2017;9(4):e503-e510

20 Buskes JA, Christoffersen J, Arends J. Lesion formation and lesion remineralization in enamel under constant composition conditions. A new technique with applications. Caries Res 1985;19(6):490-496

21 Lagerweij MD, ten Cate JM. Acid susceptibility at various depths of pH-cycled enamel and dentine specimens. Caries Res 2006;40(1):33-37

22 Buzalaf MA, Hannas AR, Kato MT. Saliva and dental erosion. J Appl Oral Sci 2012;20(5):493-502
23 Dai Z, Liu M, Ma Y, et al. Effects of fluoride and calcium phosphate materials on remineralization of mild and severe white spot lesions. BioMed Res Int 2019;2019:1271523

24 Parker AS, Patel AN, Al Botros R, et al. Measurement of the efficacy of calcium silicate for the protection and repair of dental enamel. J Dent 2014;42(Suppl 1) :S21-S29

25 Wasser G, João-Souza SH, Lussi A, Carvalho TS. Erosionprotecting effect of oral-care products available on the Swiss market. A pilot study. Swiss Dent J 2018;128(4):290-296

26 Lussi A, Buzalaf MAR, Duangthip D, et al. The use of fluoride for the prevention of dental erosion and erosive tooth wear in children and adolescents. Eur Arch Paediatr Dent 2019;20(6):517-527

27 Lussi A, Hellwig E. Risk assessment and causal preventive measures. Monogr Oral Sci 2014;25:220-229

28 Brighenti FL, Delbem AC, Buzalaf MA, Oliveira FA, Ribeiro DB, Sassaki KT. In vitro evaluation of acidified toothpastes with low fluoride content. Caries Res 2006;40(3):239-244

29 de Almeida Baldini Cardoso C, Mangueira DF, Olympio KP, et al. The effect of $\mathrm{pH}$ and fluoride concentration of liquid dentifrices on caries progression. Clin Oral Investig 2014;18(3):761-767

30 Hossain A, Okawa S, Miyakawa O. Surface texture and composition of titanium brushed with toothpaste slurries of different pHs. Dent Mater 2007;23(2):186-192

31 Larsson M, Hill A, Duffy J. Suspension Stability; Why Particle Size, Zeta potential and rheology are important. Annual Transactions of the Nordic Rheology Society; 2012:20:209-214

32 Thiemig D, Bund A. Influence of ethanol on the electrodeposition of Ni/Al2O3 nanocomposite films. Appl Surf Sci 2009;255(7):4164-4170

33 Moraschini V, da Costa LS, Dos Santos GO. Effectiveness for dentin hypersensitivity treatment of non-carious cervical lesions: a meta-analysis. Clin Oral Investig 2018;22(2):617-631

34 Akkus A, Karasik D, Roperto R. Correlation between micro-hardness and mineral content in healthy human enamel. J Clin Exp Dent 2017;9(4):e569-e573 